\title{
Science for the citizen
}

Graham Farmelo

\section{A new series of books intended to make science accessible to a mass audience has just been launched - but will they repeat the success of Stephen Hawking's A Brief History of Time?}

THE most depressing thing about today's popular science books is that they are so unpopular. Apart from a handful of blockbusters, very few of the science books written for the general public sell in substantial numbers: according to a recent survey, only two per cent of the UK population have bought a nonfiction book on science or technology within the past 12 months.

The Rhône-Poulenc Prizes for science books have done much to focus attention on fine-quality science writing, notably Steve Jones's The Language of the Genes, Jared Diamond's The Rise and Fall of the Third Chimpanzee and Stephen Jay Gould's Wonderful Life. Yet none of the winners in the prize's eight-year history has sold in vast numbers or established itself in the popular mind as an acknowledged 'good read'. Perhaps the works that are generally praised as gems of popularization are actually examples of excellent writing for other scientists or, at least, for keen and well-informed lay people.

These three attractively packaged books launch the new Science Masters series, which plainly intends to make modern science accessible to a mass audience. This much-heralded series, which is being published in 26 countries, is the ambitious brainchild of Anthony Cheetham, chairman of the Orion Publishing Group in London, and John Brockman, the New York literary agent famous for the lavish advances he is said to have secured for several eminent scientists.

Each of the volumes is short, completely (or almost completely) devoid of equations and written for a wide audience by a leading scientist. The series aims to cater for the "educated but non-specialist reader", which we are told implies that "no prior knowledge of science or mathematics is required". This is an odd statement: can someone be regarded as educated if they know no science at all?

\section{Jargon}

Scientific greenhorns will certainly struggle with the accounts of astrophysics given here by John Barrow and Paul Davies, both theoretical physicists. Given their uncommon talent for penning lively and well-informed expositions of the arcana of modern physics, it is surprising how freely they use jargon that will certainly be Greek to those with no training in science (examples: asymptote, ionized plasma, joules and kelvin). Pedagogic justice would imply that readers will not put up with this, yet sales figures of astrophysics books make it clear that there are many who are prepared to struggle with the most challenging material that the experts throw at them.

This was first demonstrated 17 years ago when the Nobel prizewinning physicist Steven Weinberg published The First Three Minutes, his best-selling account of the origins of the Universe. Paul Davies pays handsome tribute to Weinberg's pioneering book and cleverly chooses to focus on the other extreme of the Universe's life, a subject that at first seems to have similar promise. But whereas Weinberg could give a straightforward and dramatic frame-by-frame account of the birth of space, time, matter and energy, Davies has to consider several scenarios of oblivion, including a collision with a comet that ends life on Earth, the big crunch and the so-called 'deep freeze' in which the Universe slides towards degeneration "inexorably" (a favourite word in the Davies lexicon).

Davies takes what is described on the dustjacket as a "free-ranging" approach, delving into dozens of areas in modern astrophysics, several of which nonspecialists may perceive to be peripheral to the main subject. As a result, The Last Three Minutes comes over as a concatenation of well-crafted tableaux that collectively have a frustratingly hazy focus.

Davies's account would have been a good deal clearer if he had included the familiar plot of 'size' against time for the various types of expanding Universe. Such a diagram obligingly turns up in Barrow's first chapter, which expertly summarizes "the universe in a nutshell", including the gist of Davies's story. The subsequent parts briskly cover most of the key topics in contemporary cosmology including cosmic ripples, wormholes, black holes and inflation. For those who can stomach the challenge-and this cohort will include everyone who finished Stephen Hawking's A Brief History of Time - Barrow has written what is probably the best available short introduction to modern cosmology.

High-quality illustrations are crucial to the appeal of popular science books, so it is disappointing that both Davies and Barrow have been badly let down in this respect. The Last Three Minutes features far too few diagrams and the ones that are included are miserably inadequate, to say the least. Yet even these are superior to most of Barrow's illustrations, which for the most part look as though they have been scratched out using a high-school Indian ink set.

The other member of the Science Masters opening trio, Richard Leakey's agreeable The Origin of Mankind, is in every sense more down to earth than its two companions. This clear, plain-spoken account of human evolution covers not only the relationships between ourselves and our African ancestors but also the latest thinking on the development of language, consciousness and economic cooperation. Once again the standard of the illustrations is indifferent-even the chapter on art has only one unprepossessing figure.

\section{Personal view}

Leakey's account is pleasingly personal and he occasionally points out where he disagrees with orthodox views, most strikingly when he explains why he dissents from the popular interpretation of Donald Johanson and Tim White of the rich collection of fossils found two decades ago in Hadar, Ethiopia. The reasoning that underlies this and other disagreements will give nonspecialists useful insights into how and why scientists so often view a piece of evidence in different ways. A little more emotion would have added a further touch of veracity.

So the Science Masters series begins well, if not quite as strongly as we might have hoped. Our appetite has, however, been whetted for books in this format and we look can forward to contributions from Richard Dawkins, Daniel C. Dennett, Colin Blakemore and a host of other luminaries. One hopes that it will not be long before the publishers recruit Freeman Dyson, one of the most graceful essayists to have written on physical science. Meanwhile, will someone talk to whoever is responsible for the series' graphics?

Graham Farmelo is Head of Programmes at the Science Museum, Exhibition Road, London SW7 2DD, UK.

\section{Books mentioned in this review:}

The Last Three Minutes. By Paul Davies. BasicBooks/Weidenfeld and Nicholson: 1994. Pp. 162. \$20, £9.99.

The Origin of the Universe. By John D. Barrow. BasicBooks/Weidenfeld and Nicholson: 1994. Pp. 150. \$20, £9.99.

The Origin of Humankind. By Richard Leakey. BasicBooks/Weidenfeld and Nicholson: 1994. Pp. 171. \$20, £9.99. 